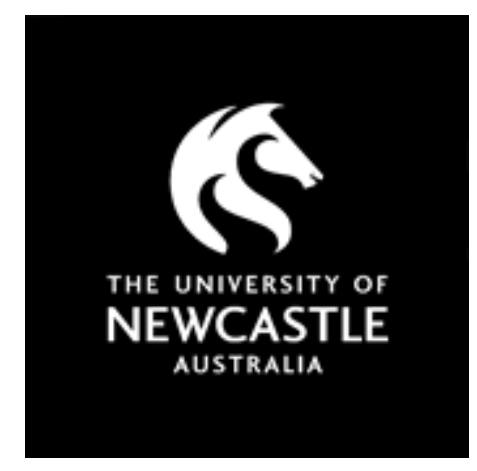

\title{
NOVA
}

University of Newcastle Research Online

nova.newcastle.edu.au

Clinton-Mcharg, Tara; Carey, Mariko; Sanson-Fisher, Rob; Tzelepis, Flora; Bryant, Jamie; Williamson, Anna 'Anxiety and depression among haematological cancer patients attending treatment centres: prevalence and predictors', Journal of Affective Disorders Vol. 165, p. 176-181 (2014)

Available from: http://dx.doi.org/10.1016/j.jad.2014.04.072 


\section{Anxiety and depression among haematological cancer patients attending treatment}

centres: prevalence and predictors

\section{Authors:}

Tara Clinton-McHarg ${ }^{{ }^{*},}$, Mariko Carey ${ }^{\text {a }}$, Rob Sanson-Fisher ${ }^{a}$, Flora Tzelepis ${ }^{\text {a }}$, Jamie Bryant a, Anna Williamson ${ }^{\mathrm{b}}$

${ }^{a}$ Priority Research Centre for Health Behaviour, University of Newcastle, Callaghan, NSW, Australia

${ }^{\mathrm{b}}$ The Leukaemia Foundation, Windsor, QLD, Australia

*Corresponding author at: Priority Research Centre for Health Behaviour, Level 4 HMRI

Building, University of Newcastle, Callaghan NSW 2308, Australia. Tel: +61 24924 6367; Fax: +612 49246209.

E-mail address: tara.clintonmcharg@hnehealth.nsw.gov.au 


\begin{abstract}
Background: This study aimed to: 1) estimate the prevalence of anxiety and/or depression among haematological cancer patients attending treatment centres; and 2) explore the demographic, disease and treatment characteristics associated with anxiety and/or depression.
\end{abstract}

Methods: A cross-sectional study was conducted with outpatients from three haematology clinics in Australia. Patients with a confirmed diagnosis of haematological cancer were approached by a research assistant while waiting for their appointment and invited to participate in the survey. Participants completed the Hospital Anxiety and Depression Scale (HADS) and self-reported demographic, disease and treatment characteristics.

Results: Questionnaires from 304 participants were returned. Twenty-seven percent of patients reported anxiety and 17\% reported depression. Specifically, 15\% reported anxiety without depression, $5 \%$ reported depression without anxiety, and 12\% reported comorbid anxiety and depression. Participants who had to relocate to receive treatment had almost three times the odds of reporting anxiety and/or depression compared to those who did not have to move. Former smokers also had significantly higher odds of reporting anxiety and/or depression.

Limitations: The HADS is likely to have produced some false positives and false negatives when compared with gold standard structured clinical interviews for assessing psychological morbidity.

Conclusions: Approximately 20\% of haematological cancer patients attending outpatient clinics may experience clinically significant levels of anxiety and/or depression. Providing 
additional tailored support to patients who have had to relocate for treatment, and to former smokers, may help to reduce anxiety and depression among these subgroups.

Keywords: anxiety; depression; cancer; haematology; treatment centre 


\section{Introduction}

Haematological cancers, which include myelomas, leukaemias and lymphomas, are estimated to account for 9\% of all cancers in the economically developed world (Smith et al., 2011). While haematological cancers can occur at any age, the likelihood of a diagnosis increases markedly for individuals who are 50 years and over (Smith et al., 2011). Haematological cancer patients may require intensive periods of treatment, including those received as an inpatient such as autologous bone marrow transplants (Montgomery et al., 2002). Debilitating side effects of cancer treatment experienced by those with haematological malignancy include fatigue, neutropenia, infection, and nausea and vomiting (Ganz et al., 2003; Pettengell et al., 2008; Montgomery et al., 2002; Mols et al., 2012). Some haematological cancers have a relapsing remitting course, which can have a significant impact on a person's family life, capacity to maintain employment and ability to plan for the future (Bellizzi et al., 2007).

In a recent study conducted by Linden and colleagues, anxiety and depression was examined among a mixed sample of cancer patients from two treatment centres. Of the 167 patients who had haematological cancer, rates of sub-clinical and clinical anxiety were $50 \%$ and $23 \%$ respectively, and rates of sub-clinical and clinical depression were $38 \%$ and $17 \%$ respectively (Linden et al., 2012). Past studies conducted with people with haematological cancers have reported rates of anxiety of between 20\% (Santos et al., 2006) and 37\% (Romito et al., 2008), and rates of depression of between 14\% and 51\% (Montgomery et al., 2003). However, these estimates of distress are limited due to the small sample sizes of these studies (Montgomery et al., 2003; Pulgar et al., 2012; Trask et al., 2002), or their lack of generalisability given that many studies have only recruited patients from one treatment centre (Santos et al., 2006; Romito et al., 2008; Akaho et al., 2003). 
One large, population-based Australian study examined the prevalence of anxiety and depression in a sample of 1323 people with mixed cancer diagnoses recruited through two state cancer registries at six months post diagnosis (Boyes et al., 2011). Among the subgroup of haematological cancer patients $(n=181)$, the reported rate of anxiety was $27 \%$, depression 17\%, and co-morbid anxiety and depression 11\% (Boyes et al., 2011). While these data provide valuable information about the psychological wellbeing of patients at six months post diagnosis, it is unclear how relevant these findings are to patients who are receiving care in an outpatient setting.

Given that outpatient appointments provide an opportunity for detection and referral, accurate information about the prevalence of anxiety and depression among haematological cancer patients in this setting is vital to inform the development and delivery of appropriate services. Further, to facilitate identification of those at risk of poor psychological outcomes, up-to-date information about factors associated with increased odds of anxiety and depression among this population are needed.

This study aimed to: 1) estimate the prevalence of anxiety and/or depression among haematological cancer patients who were currently attending treatment centres; and 2) explore the demographic, disease, and treatment characteristics associated with anxiety and/or depression.

\section{Methods}

\section{Design}


The study involved a cross-sectional survey of haematological cancer patients attending three haematology outpatient clinics located in three different Australian states.

\section{Clinic eligibility and selection}

To ensure that a large and representative sample was obtained, clinics were eligible if they provided care to at least 300 adult haematological cancer patients per annum.

\section{Patient eligibility and selection}

Eligible patients were attending an outpatient appointment at a participating clinic during the recruitment period (October 2012 to March 2013), had a diagnosis of haematological cancer, were aged 18 years or older, and were able to read and understand English. Patients deemed by their Haematologist to be physically or psychologically incapable of completing the questionnaire were excluded.

\section{Procedure}

Ethics approval was gained from the University of Newcastle Human Research Ethics Committee and ethics committees associated with each participating treatment centre. At each clinic, a Haematologist or nurse identified potentially eligible patients from the daily outpatient attendance list. A research assistant approached eligible patients, provided an information letter and sought informed consent. Consenting patients were asked to complete a pen and paper questionnaire while waiting for their appointment. Patients called into their appointment before completing the survey were able to finish the survey after their consultation, or take the survey home and return it using a reply paid envelope. One written reminder was sent to patients who had not returned their completed survey within two weeks 
of consenting to participate. The gender and age of non-consenting patients was recorded to allow the detection of any sample bias.

\section{Measures}

Participants completed a questionnaire, which consisted of the following:

Hospital Anxiety and Depression Scale (HADS): The HADS is a 14 item measure with two subscales, an ‘anxiety’ sub-scale (7 items) and a ‘depression’ sub-scale (7 items) (Zigmond and Snaith, 1983). Each item is scored from 0 to 3, giving a maximum score of 21 per subscale. A cut-off score of 8 or greater per sub-scale has been recommended as having the best sensitivity and specificity for identifying anxiety and depression (Zigmond and Snaith, 1983). The HADS meets psychometric criteria for high internal consistency and discriminant validity (Vodermaier et al., 2009), and has been validated for use with many cancer patient groups including those diagnosed with haematological cancers (Smith et al., 2002; Luckett et al., 2010). The two-factor structure of the measure has been found to remain stable across sub-groups of cancer patients at different stages of disease (Smith et al., 2002). The HADS has being recommended as the most appropriate tool for identifying clinically significant distress and depression among patients both during and after cancer treatment (Ziegler et al., 2011).

Demographic characteristics: Participants were asked to self-report their: age; gender; marital status; highest level of education; employment status; living arrangements; country of birth; indigenous background; private health insurance status; concession card holder status; and smoking status. Residential postcodes were obtained so that the geographical remoteness 
of a patient's home could be calculated using the Accessibility Remoteness Index of Australia (ARIA) (Department of Health and Aged Care, 2001).

Disease and treatment characteristics: Participants were asked to self-report: the type of haematological cancer they had been diagnosed with; the stage of their cancer (e.g. early stages of disease with few noticeable symptoms, or advanced stages of disease with many symptoms); time since diagnosis; and the types of treatment they had received. Participants also indicated whether they had relocated from their usual home in order to receive treatment.

\section{Statistical analysis}

Scoring of the HADS was undertaken using the following procedures: 1) if only one item was missing on a subscale, the mean of the remaining subscale items was imputed; 2) if more than one item was missing for a subscale, the score for the subscale was not included; 3) a score of 8 or greater on either the anxiety or depression sub-scale was used to classify people as anxious or depressed respectively; and 4) comorbid anxiety-depression was defined as patients having a score of 8 or greater on both subscales of the HADS.

The prevalence of anxiety, depression, or comorbid anxiety and depression among haematological cancer patients was described using frequencies. Chi-square analyses were used to determine whether patients’ demographic or disease and treatment characteristics were associated with anxiety and/or depression. The characteristics examined in these univariate analyses were: age; gender; marital status; highest level of education; employment status; living arrangements; country of birth; indigenous background; private health insurance status; concession card holder status; smoking status; geographical remoteness; haematological cancer type; cancer stage; time since diagnosis; treatment received; and 
relocated to receive treatment. Variables identified as having possible associations $(\mathrm{p}<0.2)$ in the univariate analyses were included in a logistic regression model with anxiety and/or depression as the outcome. Clustering of participants by treatment centre was accounted for using the Taylor series method to estimate the covariance matrix of the regression coefficients. Odds ratios and 95\% confidence intervals were calculated.

\section{Results}

Of the 428 eligible haematological cancer patients identified, 386 (90\%) consented to participate in the study. Three-hundred and four participants (71\%) returned a completed questionnaire and were included in the analysis. Non-consenters were significantly more likely to be younger than consenters $(\mathrm{p}<0.0001)$.

Participant demographic, disease and treatment characteristics are presented in Tables 1 and 2. Over half of the participants were aged between 55 and 74 years $(n=170,56 \%)$ with a higher proportion of males ( $n=175,58 \%)$. Sixty-seven percent of participants were married or had a partner, while a third of participants lived alone. Thirty-one percent of participants were born in a country other than Australia.

Lymphoma was the most commonly reported haematological cancer type ( $n=129,43 \%$ ). Thirty-six percent of participants were unsure about whether their cancer was at an early or advanced stage. Almost $60 \%$ of patients had received chemotherapy plus at least one other form of treatment. 


\section{Overall prevalence of anxiety and/or depression among participants}

Figure 1 describes the levels of anxiety, depression, and comorbid anxiety and depression among haematological cancer patients. Overall, 27\% $(n=83)$ of participants reported anxiety and $17 \%(n=52)$ reported depression. When broken down into single or comorbid disease, 15\% ( $n=47)$ of participants had anxiety without depression, 5\% $(n=16)$ had depression without anxiety and 12\% (n=36) reported comorbid anxiety and depression. Sixty-seven percent $(n=205)$ of participants were neither anxious nor depressed.

Of the 99 participants who reported anxiety and/or depression, 32\% $(n=31)$ had taken medication for anxiety or depression in the last week, and 14\% ( $\mathrm{n}=13)$ had received counselling in the last week.

\section{INSERT FIGURE 1 HERE}

\section{Factors associated with anxiety and/or depression}

Following chi-square analysis, 13 variables were identified as having possible associations $(\mathrm{p}<0.2)$ with anxiety and/or depression: age; gender; marital status; employment status; living arrangements; country of birth; private health insurance status; concession card holder status; smoking status; haematological cancer type; cancer stage; treatment received; and relocated to receive treatment (see Tables 1 and 2). Table 3 outlines the results of the final logistic regression model.

INSERT TABLE 3 HERE 
Only four groups had p values less than 0.05 and confidence intervals that did not contain 1 . Patients who had to relocate to receive treatment had almost three times the odds of reporting anxiety and/or depression compared to those who did not have to relocate (OR=2.94, [1.05, 8.24]). Former smokers also had significantly higher odds of reporting anxiety and/or depression than patients who had never smoked (OR=1.21, [1.01, 1.44]).

Patients who had private health insurance or were born overseas in an English-speaking country had lower odds of reporting anxiety and/or depression.

\section{Discussion}

\section{Prevalence of anxiety, depression and co-morbid anxiety and depression}

There are few international studies with samples large enough to provide robust estimates of the prevalence of anxiety and depression among haematological outpatients. Hence, the current study provides important data to inform psychosocial care for this population. The prevalence of anxiety (27\%) and depression (17\%) found is consistent with other studies recruiting similar patients from treatment centres (Romito et al., 2008; Santos et al., 2006; Montgomery et al., 2003). It is difficult to compare these rates of anxiety and depression to those found in the general population due to differences in measurement tools. However, the most recent Australian National Survey of Mental Health and Well-being estimated that 14\% of the general population had experienced an anxiety disorder in the past 12 months, while 6.2\% had experienced depression (Australian Bureau of Statistics, 2008). This suggests that haematological cancer patients maybe be experiencing psychological distress at a much higher rate than usually observed in the community.

\section{Factors associated with higher odds of psychological distress in blood cancer patients}


Haematological cancer patients who relocated for treatment had significantly higher odds of reporting anxiety and/or depression. There is a trend in many countries including Australia to provide treatment for complex cancers at large, city-based Comprehensive Cancer Centres (Zucca et al., 2011). While these centres are hubs for the latest specialist care, they are not easily accessible to cancer patients living in regional and remote locations. This situation may contribute to increased financial hardship for patients due to the costs associated with travel and accommodation (Zucca et al., 2011), as well as lead to isolation from their important support networks of family and friends (McGrath, 1999).

Former smokers in the current study had higher odds of reporting anxiety and/or depression compared to haematological cancer patients who had never smoked. A previous study of mixed cancer patients, including those with blood cancer, also found that current and former smokers had twice the odds of reporting comorbid anxiety and depression at one year postdiagnosis compared to non-smokers (Boyes et al., 2013). It is possible that former smokers may perceive they have fewer strategies available to help them cope with stressful situations (such as a cancer diagnosis), putting them at greater risk for psychological distress (Leung et al., 2011).

\section{Clinical implications of findings}

Given that particular subgroups of haematological cancer patients have higher odds of reporting anxiety and/or depression, there is a clear need to prioritise research which aims to: 1) accurately detect individuals most at risk of poor psychosocial outcomes in the outpatient setting; and 2) test the effectiveness of strategically designed psychological treatments and the provision of services. Based on the current findings, interventions which address practical 
concerns such as assisting with relocation and accommodation for treatment, are likely to be valuable in addressing anxiety and depression for some haematological cancer patients.

\section{Strengths and limitations}

Eligibility for the study was based on perceptions of haematologists and nurses regarding the physical and psychological well-being of their patient, and whether they felt that completing the questionnaire would cause the patient distress. Therefore, it is possible that some patients experiencing severe anxiety or depression may have been excluded from the study, leading to an underestimation of the true prevalence of anxiety and depression experienced by this population. The HADS is likely to have produced some false positives and some false negatives when compared with gold standard structured clinical interviews for assessing psychological morbidity (Carey et al., 2012). However, as the HADS is a widely employed measure (Luckett et al., 2010), the use of this validated tool enables comparisons with past studies.

When performing statistical analysis in this study, the outcome of 'anxiety and/or depression' was used. While it is recognised that anxiety and depression are separate constructs (Moorey et al., 1991) which could be associated with different individual, disease and treatment variables, the purpose of this study was to focus on individuals in the outpatient setting at risk of either type of affective disorder. A score of 8 or greater on either or both the anxiety (HADS-A) and depression (HADS-D) subscales was used in preference to a 'total HADS' score (HADS-T) as there is less evidence to support the use of a particular cut-off score for the overall measure (Luckett et al., 2010). When interpreting the results of the study, it should also be noted that the number of univariate comparisons conducted may have increased the risk of Type 1 error. However, only findings from the multivariate analyses (logistic 
regression) were used to identify associations between patient characteristics and reported anxiety and/or depression, which would minimise the limitation of conducting multiple univariate comparisons.

Strengths of the current study were the high participant consent rates and inclusion of a broad range of patients with various demographic, disease and treatment characteristics from three treatment centres. The proportion of patients in the sample with lymphoma (43\%) and leukaemia (27\%) closely reflects the annual incidence of lymphoma and leukaemia in the Australian population (43\% and 26\% of all newly diagnosed blood cancers respectively) (Australian Institute of Health and Welfare and Australasian Association of Cancer Registries, 2012). However, patients with myeloma (21\%) may have been over-represented in the study as the annual incidence for new myeloma cases is much lower in the population, comprising only $13 \%$ of all blood cancers diagnosed (Australian Institute of Health and Welfare and Australasian Association of Cancer Registries, 2012). Sampling from a larger number of treatment centres in future studies may increase the generalisability of study findings.

\section{Conclusions}

Approximately $20 \%$ of haematological cancer patients attending outpatient clinics may be experiencing clinically significant levels of anxiety and/or depression. This risk appears to be higher for patients who have to relocate to receive treatment or who are former smokers. Clinical staff should be aware of these factors and monitor patients with these characteristics carefully. Early referral to mental health professionals, and provision of practical support may help to address anxiety and depression among this population. 


\section{References}

Akaho, R., Sasaki, T., Mori, S.-I., Akiyama, H., Yoshino, M., Hagiya, K., Nakagome, K., Sakamaki, H., 2003. Psychological factors and survival after bone marrow transplantation in patients with leukemia. Psychiatry and Clinical Neurosciences 57, 91-96.

Australian Bureau of Statistics, 2008. National Survey of Mental Health and Wellbeing: Summary of Results, 2007. ABS, Canberra.

Australian Institute of Health and Welfare and Australasian Association of Cancer Registries, 2012. Cancer in Australia: An Overview, 2012. AIHW, Canberra.

Bellizzi, K. M., Miller, M. F., Arora, N. K., Rowland, J. H., 2007. Positive and negative life changes experienced by survivors of non-Hodgkin's lymphoma. Annals of Behavioral Medicine 34, 188-199.

Boyes, A. W., Girgis, A., D'Este, C., Zucca, A. C., 2011. Flourishing or floundering? Prevalence and correlates of anxiety and depression among a population-based sample of adult cancer survivors 6 months after diagnosis. Journal of Affective Disorders 135, 184-192.

Boyes, A. W., Girgis, A., D'Este, C. A., Zucca, A. C., Lecathelinais, C., Carey, M. L., 2013. Prevalence and predictors of the short-term trajectory of anxiety and depression in the first year after a cancer diagnosis: a population-based longitudinal study. Journal of Clinical Oncology 31, 2724-2729.

Carey, M., Noble, N., Sanson-Fisher, R., Mackenzie, L., 2012. Identifying psychological morbidity among people with cancer using the Hospital Anxiety and Depression Scale: time to revisit first principles? Psycho-Oncology 21, 229-238. 
Department of Health and Aged Care, 2001. Measuring Remoteness: Accessibility Remoteness Index of Australia (ARIA). Revised Edition. Commonwealth of Australia, Canberra.

Ganz, P. A., Moinpour, C. M., Pauler, D. K., Kornblith, A. B., Gaynor, E. R., Balcerzak, S. P., Gatti, G. S., Erba, H. P., McCoy, S., Press, O. W., Fisher, R. I., 2003. Health status and quality of life in patients with early-stage Hodgkin's disease treated on Southwest Oncology Group Study 9133. Journal of Clinical Oncology 21, 3512-3519.

Leung, J., Gartner, C., Dobson, A., Lucke, J., Hall, W., 2011. Psychological distress is associated with tobacco smoking and quitting behaviour in the Australian population: evidence from national cross-sectional surveys. Australian and New Zealand Journal of Psychiatry 45, 170-178.

Linden, W., Vodermaier, A., MacKenzie, R., Greig, D., 2012. Anxiety and depression after cancer diagnosis: Prevalence rates by cancer type, gender, and age. Journal of Affective Disorders 141, 343-351.

Luckett, T., Butow, P. N., King, M. T., Oguchi, M., Heading, G., Hackl, N. A., Rankin, N., Price, M. A., 2010. A review and recommendations for optimal outcome measures of anxiety, depression and general distress in studies evaluating psychosocial interventions for English-speaking adults with heterogeneous cancer diagnoses. Supportive Care in Cancer 18, 1241-1262.

McGrath, P., 1999. Accommodation for patients and carers during relocation for treatment for leukaemia: a descriptive profile. Supportive Care in Cancer 7, 6-10.

Mols, F., Oerlemans, S., Vos, A. H., Koster, A., Verelst, S., Sonneveld, P., van de PollFranse, L. V., 2012. Health-related quality of life and disease-specific complaints among multiple myeloma patients up to $10 \mathrm{yr}$ after diagnosis: results from a 
population-based study using the PROFILES registry. European Journal of Haematology 89, 311-319.

Montgomery, C., Pocock, M., Titley, K., Lloyd, K., 2002. Individual quality of life in patients with leukaemia and lymphoma. Psycho-Oncology 11, 239-243.

Montgomery, C., Pocock, M., Titley, K., Lloyd, K., 2003. Predicting psychological distress in patients with leukaemia and lymphoma. Journal of Psychosomatic Research 54, 289-292.

Moorey, S., Greer, S., Watson, M., Gorman, C., Rowden, L., Tunmore, R., Robertson, B., Bliss, J., 1991. The factor structure and factor stability of the Hospital Anxiety and Depression Scale in patients with cancer. British Journal of Psychiatry 158, 255-259.

Pettengell, R., Schwenkglenks, M., Leonard, R., Bosly, A., Paridaens, R., Constenla, M., Szucs, T. D., Jackisch, C., Impact of Neutropenia in Chemotherapy-European Study Group, 2008. Neutropenia occurrence and predictors of reduced chemotherapy delivery: results from the INC-EU prospective observational European neutropenia study. Supportive Care in Cancer 16, 1299-1309.

Pulgar, A., Garrido, S., Alcala, A., Reyes del Paso, G. A., 2012. Psychosocial predictors of immune response following bone marrow transplantation. Behavioral Medicine 38, $12-18$

Romito, F., Montanaro, R., Corvasce, C., Di Bisceglie, M., Mattioli, V., 2008. Is cancerrelated fatigue more strongly correlated to haematological or to psychological factors in cancer patients? Supportive Care in Cancer 16, 943-946.

Santos, F. R. M., Kozasa, E. H., Chauffaille, M. d. L. L. F., Colleoni, G. W. B., Leite, J. R., 2006. Psychosocial adaptation and quality of life among Brazilian patients with different hematological malignancies. Journal of Psychosomatic Research 60, 505511. 
Smith, A., Howell, D., Patmore, R., Jack, A., Roman, E., 2011. Incidence of haematological malignancy by sub-type: a report from the Haematological Malignancy Research Network. British Journal of Cancer 105, 1684-1692.

Smith, A. B., Selby, P. J., Velikova, G., Stark, D., Wright, E. P., Gould, A., Cull, A., 2002. Factor analysis of the Hospital Anxiety and Depression Scale from a large cancer population. Psychology and Psychotherapy 75, 165-176.

Trask, P. C., Paterson, A., Riba, M., Brines, B., Griffith, K., Parker, P., Weick, J., Steele, P., Kyro, K., Ferrara, J., 2002. Assessment of psychological distress in prospective bone marrow transplant patients. Bone Marrow Transplantation 29, 917-925.

Vodermaier, A., Linden, W., Siu, C., 2009. Screening for emotional distress in cancer patients: a systematic review of assessment instruments. Journal of the National Cancer Institute 101, 1464-1488.

Ziegler, L., Hill, K., Neilly, L., Bennett, M. I., Higginson, I. J., Murray, S. A., Stark, D., Compass Collaborative, 2011. Identifying psychological distress at key stages of the cancer illness trajectory: a systematic review of validated self-report measures. Journal of Pain and Symptom Management 41, 619-636.

Zigmond, A. S., Snaith, R. P., 1983. The Hospital Anxiety and Depression Scale. Acta Psychiatrica Scandinavica 67, 361-370.

Zucca, A., Boyes, A., Newling, G., Hall, A., Girgis, A., 2011. Travelling all over the countryside: travel-related burden and financial difficulties reported by cancer patients in New South Wales and Victoria. Australian Journal of Rural Health 19, 298-305. 


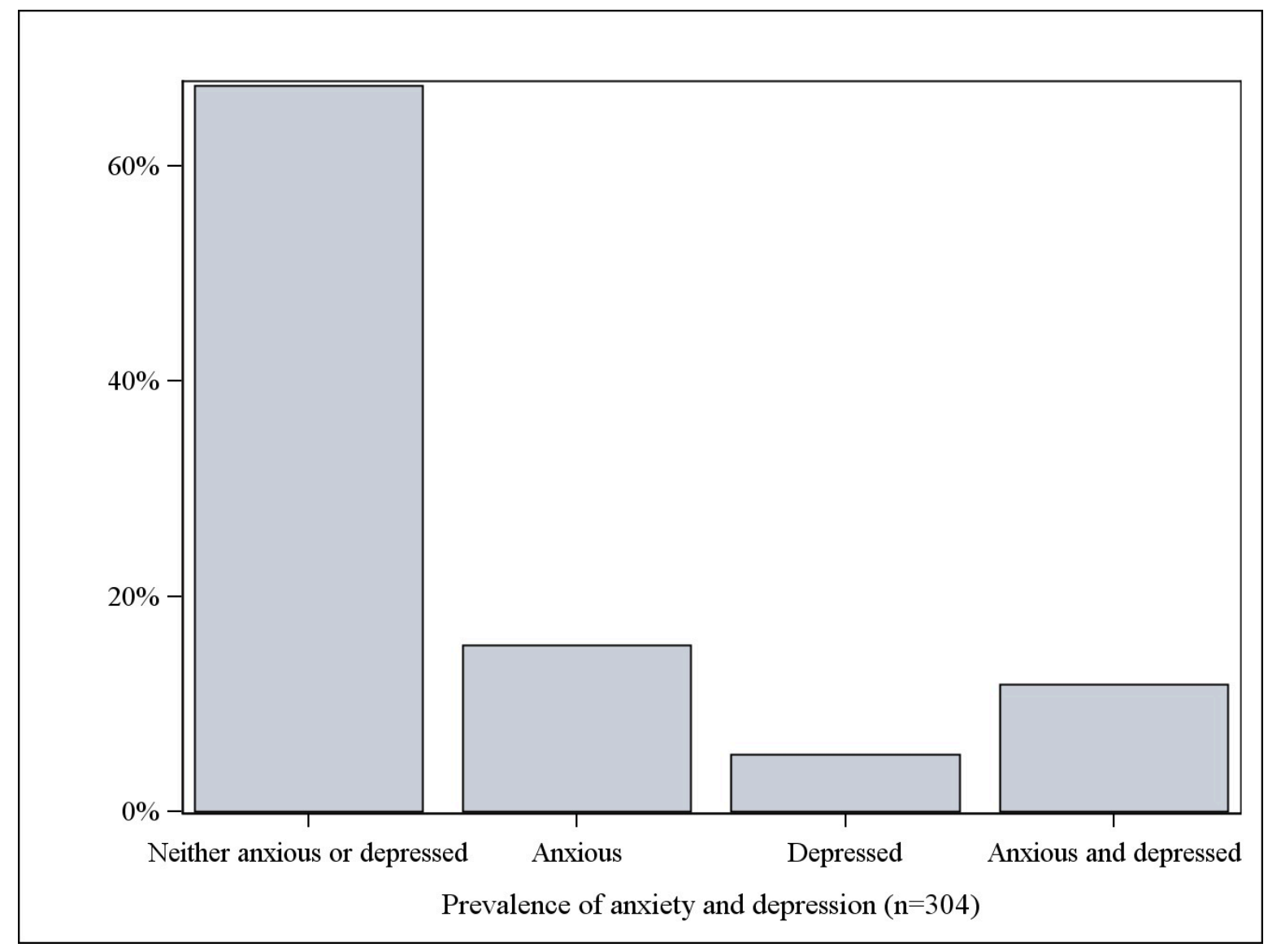

Figure 1

Overall prevalence of anxiety and depression among haematological cancer patients attending treatment clinics. 


\section{Table 1}

Demographic characteristics of participants, and univariate associations with anxiety and/or depression.

\begin{tabular}{|c|c|c|c|c|c|}
\hline \multirow[b]{2}{*}{ Demographic characteristics } & & \multirow{2}{*}{$\begin{array}{c}\begin{array}{c}\text { Cases } \\
\mathrm{n}=99\end{array} \\
\mathrm{n}(\%)\end{array}$} & \multirow{2}{*}{$\begin{array}{c}\begin{array}{c}\text { Non-Cases } \\
\mathbf{n}=205\end{array} \\
\mathbf{n}(\%)\end{array}$} & \multirow{2}{*}{$\begin{array}{c}\begin{array}{c}\text { Total } \\
\text { N=304 }\end{array} \\
\text { n (\%) }\end{array}$} & \multirow[b]{2}{*}{$p$} \\
\hline & & & & & \\
\hline \multirow[t]{3}{*}{ Age } & $<55$ & $31(31)$ & $45(22)$ & $76(25)$ & 0.0002 \\
\hline & $55-74$ & $54(55)$ & $116(57)$ & $170(56)$ & \\
\hline & $75+$ & $14(14)$ & $42(21)$ & $56(19)$ & \\
\hline \multirow[t]{2}{*}{ Gender } & Male & $51(52)$ & $124(60)$ & $175(58)$ & 0.0452 \\
\hline & Female & $48(48)$ & $81(40)$ & $129(42)$ & \\
\hline \multirow[t]{2}{*}{ Marital status } & Married/have a partner & $60(61)$ & $143(70)$ & $203(67)$ & 0.0375 \\
\hline & Single/divorced/separated/widowed & $38(39)$ & $60(30)$ & $98(33)$ & \\
\hline \multirow[t]{3}{*}{ Highest education level } & High school or below & $49(50)$ & 99 (49) & $148(49)$ & 0.3886 \\
\hline & Vocational training/trade school & $26(27)$ & $61(30)$ & $87(29)$ & \\
\hline & University & $23(23)$ & $42(21)$ & $65(22)$ & \\
\hline \multirow[t]{3}{*}{ Employment status } & Paid employment & $40(41)$ & $73(36)$ & $113(38)$ & $<0.0001$ \\
\hline & Not in labour force & $55(57)$ & $122(60)$ & $177(59)$ & \\
\hline & Unemployed & $2(2.1)$ & $8(3.9)$ & $10(3.3)$ & \\
\hline \multirow[t]{2}{*}{ Living arrangements } & With others & $73(74)$ & $161(81)$ & $234(79)$ & 0.0370 \\
\hline & Alone & $25(26)$ & $38(19)$ & $63(21)$ & \\
\hline \multirow[t]{3}{*}{ Country of birth } & Australia & $71(72)$ & $138(68)$ & 209 (69) & $<0.0001$ \\
\hline & Other country (English speaking) & $11(11)$ & $33(16)$ & $44(15)$ & \\
\hline & Other country (Non-English speaking) & $17(17)$ & $32(16)$ & $49(16)$ & \\
\hline \multirow[t]{2}{*}{ Indigenous background } & Non-Indigenous & $96(99)$ & 199 (99) & 295 (99) & 0.9853 \\
\hline & Indigenous & $1(1.0)$ & $2(1.0)$ & $3(1.0)$ & \\
\hline \multirow[t]{2}{*}{ Private health insurance } & Yes & $48(48)$ & $127(62)$ & $175(58)$ & 0.0010 \\
\hline & No & $51(52)$ & $77(38)$ & $128(42)$ & \\
\hline \multirow[t]{2}{*}{ Concession card holder } & Yes & $57(58)$ & $111(54)$ & $168(55)$ & $<0.0001$ \\
\hline & No & $42(42)$ & $93(46)$ & $135(45)$ & \\
\hline \multirow[t]{3}{*}{ Smoking status } & Current smoker & $10(10)$ & $18(8.8)$ & $28(9.2)$ & 0.0098 \\
\hline & Former smoker & $40(40)$ & $69(34)$ & $109(36)$ & \\
\hline & Never smoked & $49(49)$ & $117(57)$ & $166(55)$ & \\
\hline \multirow[t]{2}{*}{ Geographical remoteness* } & Metropolitan area & $66(67)$ & $138(69)$ & $204(68)$ & 0.2200 \\
\hline & Regional/remote area & $32(33)$ & $62(31)$ & $94(32)$ & \\
\hline
\end{tabular}

*Geographical remoteness was categorised as Metropolitan (ARIA+ Index $\leq 0.2)$ or Regional/ Remote $($ ARIA+ Index $>0.2)$ 


\section{Table 2}

Disease and treatment characteristics of participants, and univariate associations with anxiety and/or depression.

\begin{tabular}{|c|c|c|c|c|c|}
\hline & & $\begin{array}{l}\text { Cases } \\
\mathrm{n}=99\end{array}$ & $\begin{array}{c}\text { Non-Cases } \\
n=205\end{array}$ & $\begin{array}{c}\text { Total } \\
\text { N=304 }\end{array}$ & \\
\hline Disease and Treatment Chara & istics & n (\%) & n (\%) & n (\%) & $p$ \\
\hline Haematological cancer type & Lymphoma & $46(46)$ & $83(41)$ & $129(43)$ & 0.1445 \\
\hline & Leukaemia & $26(26)$ & $56(28)$ & $82(27)$ & \\
\hline & Myeloma & $19(19)$ & $45(22)$ & $64(21)$ & \\
\hline & Other blood cancers & $8(8.1)$ & 17 (8.5) & $25(8.3)$ & \\
\hline Cancer stage & Early & $35(36)$ & $85(42)$ & $120(40)$ & 0.0003 \\
\hline & Advanced & $30(31)$ & $42(21)$ & $72(24)$ & \\
\hline & Don’t know & $32(33)$ & $74(37)$ & $106(36)$ & \\
\hline Time since diagnosis & $\leq 12$ months & $29(29)$ & $53(26)$ & $82(27)$ & 0.2314 \\
\hline & 13-24 months & $18(18)$ & $40(20)$ & $58(19)$ & \\
\hline & $>24$ months & $52(53)$ & $111(54)$ & $163(54)$ & \\
\hline Treatment received & Chemotherapy only & $17(17)$ & $47(24)$ & $64(21)$ & $<0.0001$ \\
\hline & Chemotherapy and other treatment & $60(61)$ & $113(57)$ & $173(58)$ & \\
\hline & Other treatment only & $11(11)$ & $19(9.5)$ & $30(10)$ & \\
\hline & No treatment & $11(11)$ & $20(10)$ & $31(10)$ & \\
\hline Relocated to receive treatment & Yes & $18(18)$ & $14(6.8)$ & $32(11)$ & 0.0263 \\
\hline & No & $81(82)$ & $191(93)$ & 272 (89) & \\
\hline
\end{tabular}




\section{Table 3}

Final logistic regression model for characteristics associated with anxiety and/or depression in haematological cancer patients.

\begin{tabular}{|c|c|c|c|}
\hline Variable & Category & Odds ratio & Adjusted $p$ value \\
\hline \multirow[t]{3}{*}{ Age } & $<55$ & reference & 0.3026 \\
\hline & $55-74$ & $0.66(0.37,1.19)$ & \\
\hline & $75^{+}$ & $0.49(0.08,3.01)$ & \\
\hline \multirow[t]{2}{*}{ Gender } & Male & reference & 0.0744 \\
\hline & Female & $1.59(0.96,2.64)$ & \\
\hline \multirow[t]{2}{*}{ Marital status } & Married/have a partner & reference & 0.5065 \\
\hline & Single/divorced/separated/widowed & $1.36(0.55,3.39)$ & \\
\hline \multirow[t]{3}{*}{ Employment status } & Not in labour force & reference & $<0.0001$ \\
\hline & Paid employment & $1.29(0.59,2.86)$ & \\
\hline & Unemployed & $0.64(0.18,2.27)$ & \\
\hline \multirow[t]{2}{*}{ Living arrangements } & With others & reference & 0.9623 \\
\hline & Alone & $0.97(0.30,3.15)$ & \\
\hline \multirow[t]{3}{*}{ Country of birth } & Australia & reference & 0.0552 \\
\hline & Other country (English speaking) & $0.68(0.49,0.95)^{*}$ & \\
\hline & Other country (Non-English speaking) & $1.37(0.89,2.11)$ & \\
\hline \multirow[t]{2}{*}{ Private health insurance } & No & reference & 0.0464 \\
\hline & Yes & $0.59(0.35,0.99)^{*}$ & \\
\hline \multirow[t]{2}{*}{ Concession card holder } & Yes & reference & 0.0464 \\
\hline & No & $0.86(0.74,1.00)$ & \\
\hline \multirow[t]{3}{*}{ Smoking status } & Never smoked & reference & $<0.0001$ \\
\hline & Current smoker & $0.89(0.37,2.11)$ & \\
\hline & Former smoker & $1.21(1.01,1.44)^{*}$ & \\
\hline \multirow[t]{4}{*}{ Haematological cancer type } & Lymphoma & reference & $<0.0001$ \\
\hline & Leukaemia & $1.11(0.41,2.99)$ & \\
\hline & Myeloma & $0.70(0.40,1.22)$ & \\
\hline & Other blood cancers & $0.77(0.12,5.00)$ & \\
\hline \multirow[t]{3}{*}{ Cancer stage } & Early & reference & $<0.0001$ \\
\hline & Advanced & $2.13(0.94,4.84)$ & \\
\hline & Don’t know & $1.06(0.57,1.98)$ & \\
\hline \multirow[t]{4}{*}{ Treatment received } & Chemotherapy and other treatment & reference & $<0.0001$ \\
\hline & Chemotherapy only & $0.58(0.27,1.25)$ & \\
\hline & Other treatment only & $1.18(0.44,3.19)$ & \\
\hline & No treatment & $1.17(0.64,2.15)$ & \\
\hline \multirow[t]{2}{*}{ Relocated to receive treatment } & No & reference & 0.0405 \\
\hline & Yes & $2.94(1.05,8.24)^{*}$ & \\
\hline
\end{tabular}

*Groups with confidence intervals that did not contain 1 